\title{
The rapid determination of carcass fat by the Foss-Let specific gravity technique
}

\author{
BY C. J. H. WOODWARD, P. TRAYHURN AND W. P. T. JAMES \\ Dunn Nutrition Unit, University of Cambridge and Medical Research \\ Council, Milton Road, Cambridge $C B_{4}$ I $X \mathscr{J}$ \\ (Received 26 fuly 1976 - Accepted Iо August 1976)
}

\begin{abstract}
1. Carcass fat was determined by extraction with tetrachloroethylene and measurement of the solvent's change in density. The results were comparable in precision to those of a reference method; the new method extracted storage lipid but little structural lipid.

2. The technique is simple, rapid and appropriate for many nutritional studies.
\end{abstract}

The standard methods for determining fat, such as extraction in the Soxhlet apparatus and gravimetric estimation, tend to be time-consuming, and use inflammable organic solvents. A technique which overcomes these difficulties has been developed by Foss Electric Ltd for the food and agricultural industries (Usher, Green \& Smith, I973). Fat is extracted into tetrachloroethylene (TCE), and the resulting fall in the specific gravity of the solvent is measured in a magnetic float cell. The technique has been evaluated with foodstuffs (Usher et al. 1973; Egberg, Potter \& Honold, 1974; Pettinati \& Swift, 1975). The deviation from the reference methods was rarely more han I $\%$ fat content, and the reproducibility was comparable.

The present study assessed the usefulness of the procedure for the analysis of laboratory animal carcasses. Eleven mouse carcasses (Aston Strain) were freeze-dried minced and assayed in duplicate. Three of the carcasses were of obese (obob) mice. The precision and accuracy of the technique were determined by comparing the results with a gravimetric reference method applied to the same carcasses.

\section{METHODS AND MATERIALS}

\section{Chemicals}

Tetrachloroethylene (reagent grade) and ammonium sulphate were obtained from BDH Chemicals Ltd, Poole, Dorset. Organic solvents used for the reference method of fat extraction and for chromatography were from May \& Baker Ltd, Dagenham. Essex, and Silica Gel was obtained from E. Merck AG, Darmstadt, West Germany (Kiesel Gel GF 254 Typ 60).

\section{Extraction of fat with TCE}

Weighed samples of 2-3 $\mathrm{g}$ freeze-dried carcass were extracted with $3 \circ \mathrm{ml}$ TCE at room temperature using a standard blade homogenizer (MSE Ltd, Crawley, Sussex) at $1000-2000 \mathrm{rev} / \mathrm{min}$ for $2 \mathrm{~min}$. (A dry sample is necessary to avoid emulsification). The extracts were then filtered through Whatman 541 paper into a Buchner flask. 
The carcass residue was recovered, rehomogenized with a further $30 \mathrm{ml}$ solvent, and filtered. The two filtrates were transferred to a $100 \mathrm{ml}$ volumetric flask. A further $30 \mathrm{ml}$ of TCE was taken to rinse the apparatus and then added to the volumetric flask. The three combined filtrates were made up to volume, shaken, and allowed to stand. Any solid matter which collected on the surface was removed by aspiration with a Pasteur pipette.

\section{Foss-Let estimation}

The specific gravity of the extracts was measured in the Foss-Let ${ }_{53} 3$ Io instrument (Foss Electric U.K. Ltd, The Chantry, Bishopthorpe, York $\mathrm{YO}_{2} \mathrm{IQF}$ ).

To calculate the percentage of fat in the sample, the manufacturer supplies a conversion table, the validity of which has been verified by Usher et al. (1973) and by ourselves.

\section{Reference method}

Weighed samples of 2-3g carcass were analysed by a method based on that of Southgate (1971). Each sample was extracted with 3 volumes of $50 \mathrm{ml}$ of a mixture of chloroform and methanol $(2: \mathrm{I}, \mathrm{v} / \mathrm{v})$. The procedure was essentially the same as that for the TCE extraction. Solvent was removed from the pooled filtrates using a rotary evaporator. The crude fat extract which remained was then taken up by shaking with two $5^{\circ} \mathrm{ml}$ volumes of boiling petroleum ether (boiling range $40-60^{\circ}$ ). The petroleum ether was transferred to a volumetric flask, made up to $100 \mathrm{ml}$, shaken, and allowed to stand until clear. Samples ( $15 \mathrm{ml}$ ) were removed and left to evaporate at room temperature in tared foil dishes which were then reweighed.

\section{Thin-layer chromatography}

In order to assess the specificity of the TCE extraction procedure the extracts were subjected to thin-layer chromatography.

Glass plates $(20 \mathrm{~cm} \times 10 \mathrm{~cm})$ were spread with a $250 \mu \mathrm{m}$ thick layer of silica gel and activated by heating in an oven at $110^{\circ}$ for $\mathrm{I} h$. The following lean carcass extracts were applied: (i) whole dry carcass in TCE, (ii) whole dry carcass extracts made by the reference method, (iii) extracts made by the reference method from the residue left after TCE extraction. Each plate was spotted with the three extracts from a single carcass; all three spots in a set contained amounts of lipid corresponding to the content of similar weights of dry carcass. The extracts of whole dry carcass were applied in volumes containing about I $\mathrm{mg}$ lipid. The plates were developed in a solvent system of chloroform-methanol-water (I4:6:I, by vol; Muldner, Wherrett \& Cumings, 1962); this procedure yields a one-dimensional separation by class, in which the polar lipids are less mobile. The separated lipids were visualized on the plate by spraying with $4 \mathrm{M}$-aqueous ammonium sulphate (Smith, 1969) and heating in an oven at $160^{\circ}$ for I $h$.

\section{RESULTS}

Table 1 gives the results for both methods of determination. The mean difference ( \pm SEM) between duplicates was $3.1 \pm 0.9 \%$ and $2 \cdot 2 \pm 0.9 \%$ for the Foss-Let and reference methods respectively. The Foss-Let procedure consistently gave a lower 
Table I. Results for determination of fat in eleven dried mouse carcasses by Foss-Let and reference methods

(Each result is the mean of two determinations. The average difference* between duplicates was $3 \cdot 1 \pm 0.9 \ddagger$ and $2 \cdot 2 \pm 0.9 \pm \%$ for the Foss-Let and reference methods respectively)

\begin{tabular}{|c|c|c|c|}
\hline \multirow[b]{2}{*}{ Carcass } & \multicolumn{2}{|c|}{ Fat content $(\mathrm{g} / \mathrm{kg})$} & \multirow[b]{2}{*}{$\%$ difference } \\
\hline & Foss-Let & $\begin{array}{l}\text { Reference } \\
\text { method }\end{array}$ & \\
\hline $\mathbf{I}$ & 371 & $387 \S$ & $4 \cdot 2$ \\
\hline 2 & 386 & $386 \S$ & 0.0 \\
\hline 3 & 434 & $464 \S$ & 6.7 \\
\hline 4 & 378 & 475 & $22 \cdot 8$ \\
\hline 5 & 298 & $3^{67}$ & 20.8 \\
\hline 6 & 358 & 416 & $15 \cdot 0$ \\
\hline 7 & 374 & $45 I$ & $18 \cdot 7$ \\
\hline 8 & 348 & 399 & 13.7 \\
\hline $9 \dagger$ & 727 & 753 & $3 \cdot 5$ \\
\hline Iot & 839 & 877 & 44 \\
\hline IIt & 855 & 873 & $2 \cdot I$ \\
\hline $\begin{array}{l}* \% \text { difference } \\
+ \text { Carcass from } \\
\text { † Mean } \pm \text { SEN } \\
\S \text { Petroleum }\end{array}$ & $\begin{array}{l}\text { ulated as } \\
\text { sese mouse }\end{array}$ & $\frac{\text { ce between }}{\text { gean of resu }}$ & Its $\times 100( \pm$ \\
\hline
\end{tabular}

result, the average deficit for the eight lean carcasses being $12 \cdot 7 \%$ of the fat content. This difference suggested that the two methods, when conducted in full, might extract different types of lipid particularly since the difference was much smaller in the case of the three obob carcasses $(3.3 \%$ of the fat content) which have a much higher ratio of storage to structural lipid. This possibility was tested by qualitative analysis of the three types of extract with thin-layer chromatography.

Plate I shows a typical separation. The reference method extracts both neutral and structural lipids, while TCE extracts much neutral but little polar lipid. TCE also extracts a lipid which migrates just behind triglyceride in a position corresponding to cholesterol ester. The reference method when applied to the residue remaining after extraction with TCE, resulted in the removal of polar lipid but only trace amounts of triglyceride.

\section{DISCUSSION}

The quantitative analyses show that the Foss-Let method is almost as precise as the reference method, but it gives a lower value. When the material extracted by the reference method from the carcass residue remaining after extraction with TCE was determined gravimetrically, the values obtained accounted for the difference between the two methods of carcass analysis. Further extractions with TCE did not, however, increase the value obtained by the Foss-Let procedure. It therefore seemed probable that the reference method resulted in the extraction of lipids which were not extractable by TCE. 
This was confirmed by separating the material obtained from the Foss-Let and reference procedures by thin-layer chromatography. Although TCE readily extracted triglyceride and other neutral lipids, it removed little of the polar structural lipid that was extracted by the reference method. The application of the reference method to material which had previously been extracted with TCE resulted in the removal of the structural lipid. The low values for carcass fat obtained with the Foss-Let procedure are therefore clearly due to the inability of TCE to extract polar lipids.

Other work using the Foss-Let procedure has shown that the method gives lower results when materials rich in structural lipids are being assayed. Pettinati \& Swift (1975) found a deficit with meat samples containing less than $7.5 \%$ fat and Usher et al. (1973) reported reduced values with dried egg and milk powder. We have ourselves found that TCE extracts only half as much lipid as our reference method from rat brain, a tissue which contains abundant structural lipid but little triglyceride.

Conversely, obese mouse carcasses, which contain a higher proportion of storage to structural lipid, show a smaller deficit than lean carcasses (Table r). For most work, and particularly in studies on obesity, measurement of storage lipid is more relevant than that of total lipid. The Foss-Let procedure is therefore highly appropriate. With its short analytical time (about ro $\mathrm{min}$ ) it should prove to be a powerful tool in carcass analysis.

We are grateful to Mr G. Hudson and Mr P. John for suggesting that the Foss-Let procedure might be useful in carcass analysis. C.J.H.W. acknowledges the receipt of a Research Studentship from the MRC.

\section{REFEREN CES}

Egberg, D. C., Potter, R. H. \& Honold, G. R. (1974). F. Fd Sci. 39, 126 I.

Muldner, H. G., Wherrett, J. R. \& Cumings, J. N. (1962). F. Neurochem. 9, 607.

Pettinati, J. D., \& Swift, C. E. (1975). F. Assoc. off. Analyt. Chem. 58, I I82.

Smith, I. (Ed.) (1969). Chromatographic \& Electrophoretic Techniques, 3rd ed, vol. r, p. 8I. London: Heinemann.

Southgate, D. A. T. (197r). F. Sci. Fd Agric. 22, 590.

Usher, C. D., Green, C. J. \& Smith, C. A. (1973). F.Fd Technol. 8, 429.

\section{EXPLANATION OF PLATE}

Separation by thin-layer chromatography of three lipid extracts of lean mouse carcass. $\mathbf{I}=$ Extract of whole dry carcass made by reference method. 2 = Extract of whole dry carcass in tetrachloroethylene. $3=$ Extract made by reference method from residue left after tetrachloroethylene extraction. The solvent system was chloroform-methanol-water (14:6:1, by vol.), and the separation was visualized by spraying with $4 \mathrm{M}$-aqueous ammonium sulphate and heating at $160^{\circ}$ for $\mathrm{I} \mathrm{h}$. 
British Fournal of Nutrition, Vol. $3^{6, \text { No. } 3}$

Plate I

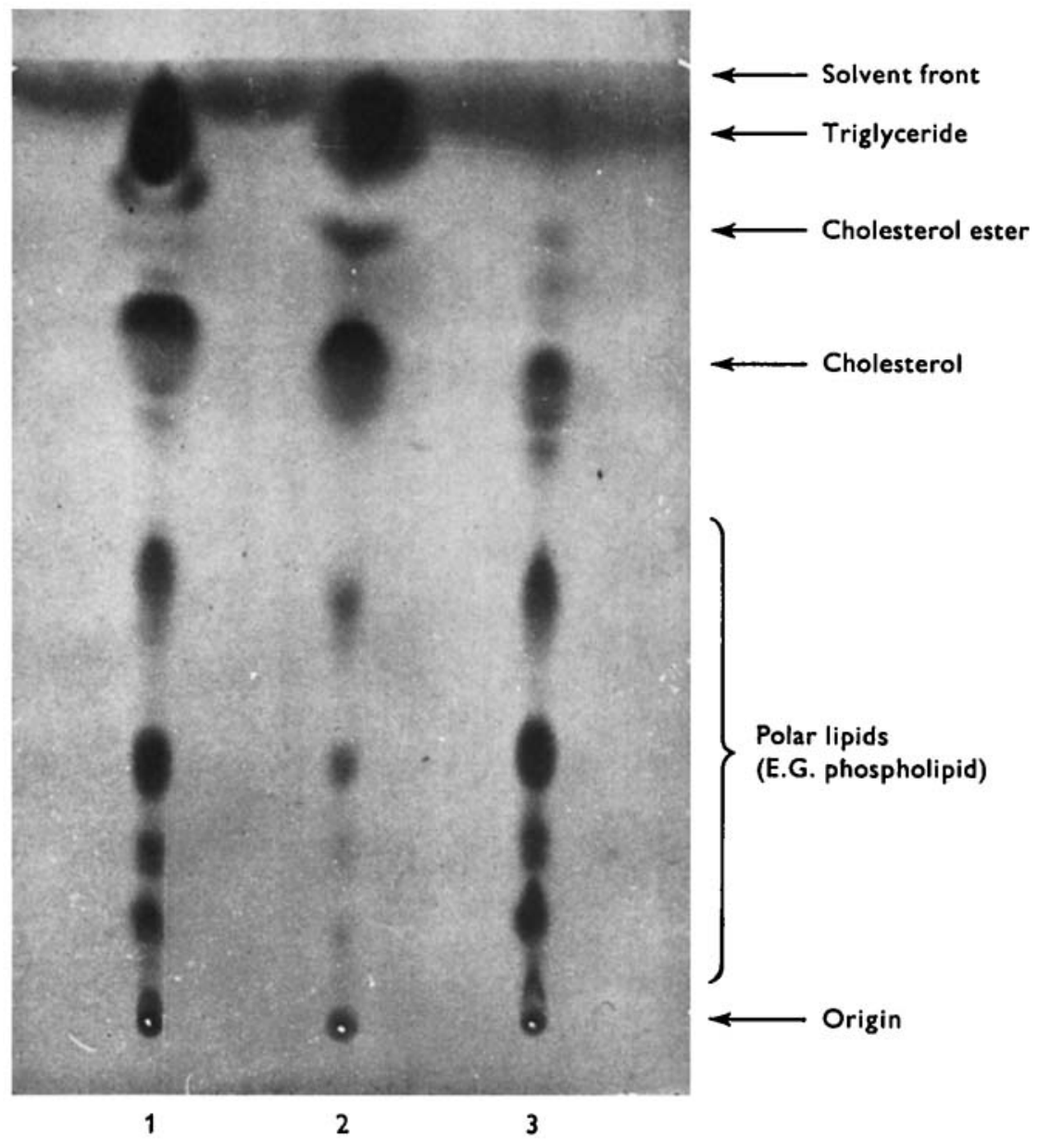

C. J. H. WOODWARD, P. TRAYHURN AND W. P. T. JAMES 